\title{
Plenary Lecture
}

\section{Herbal medicine: the science of the art}

\author{
Ann F. Walker \\ Hugh Sinclair Unit of Human Nutrition, School of Food Biosciences, University of Reading, Reading RG6 6AP, UK
}

\begin{abstract}
In the last 50 years science has provided new perspectives on the ancient art of herbal medicine. The present article discusses ways in which the evidence base for the professional use of 'Western' herbal medicine, as therapy to treat disease, known as phytotherapy, can be strengthened and developed. The evidence base for phytotherapy is small and lags behind that for the nutritional sciences, mainly because phytochemicals are ingested as complex mixtures that are incompletely characterised and have only relatively recently been subject to scientific scrutiny. While some methodologies developed for the nutritional sciences can inform phytotherapy research, opportunities for observational studies are more limited, although greater use could be made of patient case notes. Randomised clinical trials of single-herb interventions are relatively easy to undertake and increasing numbers of such studies are being published. Indeed, enough data are available on three herbs (ginkgo (Ginkgo biloba), St John's wort (Hypericum perforatum) and saw palmetto (Serenoa repens)) for meta-analyses to have been undertaken. However, phytotherapy is holistic therapy, using lifestyle advice, nutrition and individually-prescribed mixtures of herbs aimed at reinstating homeostasis. While clinical experience shows that this approach is applicable to a wide range of conditions, including chronic disease, evidence of its efficacy is scarce. Strategies for investigating the full holistic approach of phytotherapy and its main elements are discussed and illustrated through the author's studies at the University of Reading.
\end{abstract}

Phytotherapy: Herbal medicine: Complementary medicine: Integrated medicine

'Western' herbal medicine, as practised in the UK, uses herbs not only from European origin, but from many parts of the world. Trade between Europe and the East in culinary spices and herbs and later European migrations to the Americas, Africa and Australia added contributions to the materia medica. However, most impact came from North America (Griggs, 1997). In the 18th century English colonists, often bereft of qualified medical attention, combined native tradition with folklore from the 'old country'. Nascent botanical-based therapies arising from these inauspicious beginnings, had, by the middle of the 19th century, achieved considerable sophistication. This knowledge, including the use of North American herbs, was transferred to UK herbalists in the mid-1800s, primarily by herbal practitioner Albert Coffin, and these herbs are still used today by herbal practitioners in the UK. More recently, facilitated by internet communication, further contributions to the materia medica have come from Chinese traditional and Ayurvedic medicine systems.

Early clinical studies from the 1950s into the therapeutic attributes of herbal medicines were mostly conducted in Germany and documented in German. Indeed, it is only relatively recently that German studies on effects of medicinal plants have been published in English or studies undertaken in other countries. Although increasing, the evidence base for the efficacy of herbal medicine is small compared with that of nutrition. The present article will describe the ways in which the evidence base might be developed and what knowledge might be transferred from the nutritional sciences. Since the term 'herbal medicine' means both the botanical materia medica and the practice of herbal medicine, the term phytotherapy will be used to describe the latter.

Corresponding author: Dr Ann Walker, fax +44 118966 6930, email a.f.walker@reading.ac.uk 
Table 1. Examples of health problems which can benefit from phytotherapy

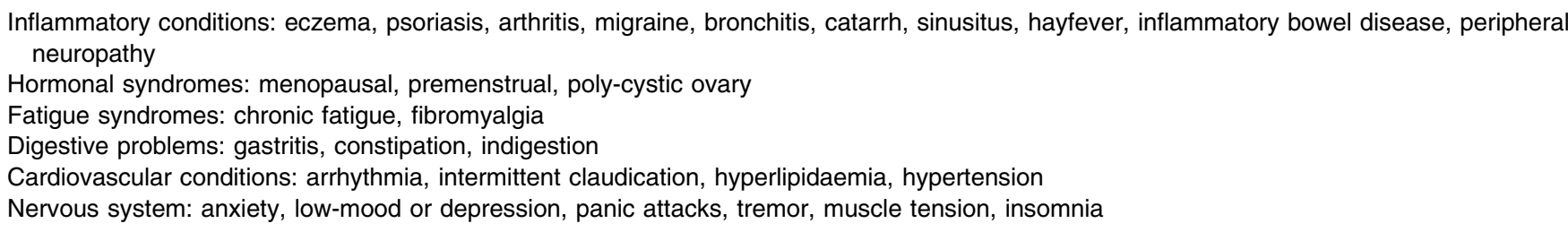

\section{The current situation}

Phytotherapy is currently practised in the UK under the 1968 Medicines Act (UK Parliament, 1977), which replaced the 1542 Act of Parliament introduced by Henry VIII to protect herbalists from prosecution (Griggs, 1997). In the 1968 Medicines Act there is a provision for the prescription and supply of herbal medicine by a herbalist, although no professional qualifications were defined (Griggs, 1997). To further protect the public, discussions are currently underway between the professional bodies that represent herbal practitioners and the Department of Health to develop a system of statutory self-regulation of herbal practitioners for accrediting training courses and monitoring professional conduct.

Over the last 10 years training in phytotherapy has evolved into the degree-level courses now based at several universities in the UK. The training elements comprise those commonly encountered in a medical degree, as well as botany, materia medica, phyto-pharmacology, phytotherapeutics and nutrition. Registration as a herbal practitioner requires $500 \mathrm{~h}$ of clinical training. As the therapeutic approach is holistic, requiring a full medical history, patient consultations normally take about $1 \mathrm{~h}$. The therapeutic aim is restoration of homeostasis by targeting the underlying causes of illness through lifestyle counselling, nutrition and individually-prescribed herbal mixtures (typically three to six herbs; Mills \& Bone, 2000). This holistic therapy is, as required, integrated with modern medication. Hence, the intervention is complex, which is problematic when seeking to enhance the evidence base for its efficacy.

A herbal practitioner most commonly prescribes herbs in liquid form as aqueous-alcoholic tinctures (i.e. as an aqueous-alcoholic extract of the herb; Bone, 2003). Occasionally, tisanes (i.e. a tea made by infusion of the herb with boiling water), powdered herb capsules or herb extract tablets may be used. Examples of conditions that respond well to phytotherapy are given in Table 1 . An example case history will illustrate how the intervention is applied (Table 2). The individual, $\mathrm{KC}$, was a 64-year-old man with X-ray evidence of severe osteoarthritis in both hips, who also complained of shoulder pain and headaches. The consultation was in December 2004, shortly after a hospital specialist had recommended an assessment for a right-hip replacement in May 2005. The dietary advice was to increase intake of dairy products, oily fish and wholegrain cereals. Potential nutrient deficits were addressed with a multinutrient supplement, including antioxidants, fish oil and glucosamine, aimed at reducing inflammatory tendency. In addition, a mixture of herbs with antiinflammatory or diuretic properties (Mills \& Bone, 2000)

Table 2. Case study of patient $\mathrm{KC}$ suffering with acute osteoarthritis: progress during treatment with phytotherapy for 6 months

\begin{tabular}{|c|c|c|c|}
\hline Patient details & $\begin{array}{l}\text { Presentation at 1st } \\
\text { consultation Dec } 2004\end{array}$ & $\begin{array}{l}\text { Nutritional advice and nutrients } \\
\text { and herbal medicine prescribed }\end{array}$ & Outcome \\
\hline $\begin{array}{l}\text { Male, } 64 \text { years, non-smoker } \\
\text { Diet: eats plenty of fruit and } \\
\text { vegetables but low } \\
\text { intake of dairy products and } \\
\text { oily fish } \\
\text { Prescribed medication: none }\end{array}$ & $\begin{array}{l}\text { OA in both hips. } \\
\text { Left hip scored as severe by } \\
\text { specialist }(7 / 10) \text {. To be } \\
\text { assessed for surgery in } 5 \\
\text { month's time. Some days he } \\
\text { cannot walk } \\
\text { Hip pain disturbs sleep } \\
\text { Other health concerns: left } \\
\text { shoulder pain and headaches }\end{array}$ & $\begin{array}{l}\text { Dietary advice: } \\
\text { } \text { Dairy products } \\
\uparrow \text { Whole grains } \\
\text { } \text { Oily fish } \\
\text { Nutrient supplements (as tablets } \\
\text { or capsules): } \\
\text { Multinutrient } \\
\text { Vitamins C and E } \\
\text { Glucosamine } \\
\text { Fish oil } \\
\text { Herbal medicine (as a mixture of } \\
\text { tinctures): } \\
\text { Devil's claw root } \\
\text { Meadowsweet herb } \\
\text { Guaiacum gum } \\
\text { Willow bark } \\
\text { Turmeric root } \\
\text { Gravel root }\end{array}$ & $\begin{array}{l}\text { Mar 2005: } \\
\text { Times of no pain in left hip } \\
\text { No pain in shoulder } \\
\text { May 2005: } \\
\text { Hip 'at its best for years'. } \\
\text { Slight ache occasionally in } \\
\text { left hip } \\
\text { Surgery postponed } \\
\text { No headaches }\end{array}$ \\
\hline
\end{tabular}

$\uparrow$, Increase intake; OA, osteoarthritis; EFA, essential fatty acids; devil's claw, Harpagophytum procumbens D.C.; meadowsweet, Filipendula ulmaria; willow, Salix spp.; turmeric, Curcuma longa; guaiacum, Guaiacum officinale; gravel root, Eupatorium purpureum. 
was prescribed, including devil's claw (Harpagophytum procumbens), meadowsweet (Filipendula ulmaria), willow (Salix spp.) bark, turmeric (Curcuma longa), guaiacum (Guaiacum officinale) gum and gravel (Eupatorium purpureum) root. By March 2005 the shoulder pain had gone and hip pain was less. By May 2005 the hip pain was reduced to a slight ache and $\mathrm{KC}$ was able to postpone surgery.

A herbal medicine does not exert its physiological action through a single mechanism, as do many modern drugs. On the contrary, the action of any herb is multifaceted, reflecting compositional plurality (Williamson, 2003). As with foods, botanical medicines are consumed according to tradition of use; there being no legal requirements for toxicological testing. Following the implementation of the EC Directive 2004/24/EC on traditional herbal medicinal products (European Commission, 2004) from November 2005, documented evidence of traditional use in the EC and safety data are required before registration of a herbal product, but not evidence of efficacy. However, a stronger evidence base is required to elevate the current status of botanical medicines in society. Only in this way can phytotherapy take its place as an important partner in integrative medicine.

\section{Evolution of a phytotherapy science base: lessons from nutritional science}

Over the last century nutritional science has developed a strong and evolving evidence base, some of the methodologies of which can be used to inform those researching into herbal medicine. The earliest nutritional studies were focused on the identification of the finite number of nutrients required to sustain life. Epidemiology developed in earnest from the 1970s and has been important in giving direction to potential associations between diet and disease to be confirmed by experimental methods. It is now accepted that, although epidemiology cannot definitively prove a connection between diet and disease, it can emphasise links to explore further through experiment. In contrast, herbal medicine offers less opportunity for observational studies as, unlike food, the general population are not commonly consuming herbs on a regular basis. Several surveys of herbal use have been undertaken (for example, see Nicolaou \& Johnston, 2004), but none have linked intake to any disease condition and, so far, little use has been made of treatment outcome from patient records.

By the 1970s clinical studies were well established in nutritional science, and many focused on single-nutrient interventions, relatively easy to blind, with specified outcomes such as physiological biomarkers. These studies provided, and continue to provide, the opportunity to elucidate the mechanisms of action, as required for scientific integrity and progress. More recently, however, wellconducted dietary studies with patient-orientated outcomes, such as the Dietary Approaches to Stop Hypertension Study (Sacks et al. 1999) have been introduced. These studies can have more immediate relevance to patient care than single-nutrient studies, even though they generate little information on mechanisms. There is clearly a place for both lines of enquiry in nutrition and this multifaceted approach to research provides a model to develop the evidence base for phytotherapy.

In contrast to nutrition, the basis of herbal medicine depends exclusively on the action of non-essential nutrients, the phytochemicals. The complexity and multitude of these compounds found in plant tissues means that component identification has been relatively recent (depending on modern developments in instrumentation) and is still far from complete. The traditional interventions of phytotherapy are crude extracts of plants as tisanes, decoctions (made by boiling dense herbal materials, such as roots, with water) or tinctures. Although a considerable science base exists on the physiological effects of isolated phytochemicals (mostly derived from animal studies), these data have limited application to an evidence base for phytotherapy, because each plant has several (or many) physiologically-active components and synergism between them should be anticipated (Williamson, 2001).

\section{Meta-analyses on single herbal extracts}

Numerous randomised double-blind clinical studies have been undertaken on single-herb extracts since the 1980s, mostly in Germany (European Scientific Cooperative on Phytotherapy, 2003). Indeed, for ginkgo (Ginkgo biloba), St John's wort (Hypericum perforatum) and saw palmetto (Serenoa repens) data have been sufficient to undertake meta-analyses.

Ginkgo-leaf extract was developed from the 1950s as a herbal medicine in Germany to treat memory loss. This relatively modern use is well supported by pharmacological evidence as well as clinical trials, and beneficial effects on the circulatory system have been shown (European Scientific Cooperative on Phytotherapy, 2003). The extract is unusual among herbal extracts in that it is a "narrowspectrum' crude extract produced commercially by selective solvent extraction to achieve a 50:1 extract (fifty parts by weight of dried leaf being equivalent to one part by weight of extract), high in ginkgolides and bilobalide, the active compounds. Concluding their meta-analysis of trials of ginkgo-extract intervention for memory loss, Birks et al. (2002) stated '.. there is promising evidence of improvement in cognition and function ...'.

St John's wort is a herb of European origin that has been used since antiquity. Although its actions include modulation of immune function and anti-inflammatory and antiviral effects, modern research has focused on its antidepressant properties. The research has been carried out on 'full-spectrum' extracts of approximately 5:1 (five parts by weight of dried leaf being equivalent to one part by weight of extract), with guaranteed (standardised) amounts of hypericin, a key active compound. Two meta-analyses have been reported. Kasper \& Dienel (2002) found that the herb '... . reduced the symptoms of depression more effectively than placebo', while Linde et al. (2005) concluded that 'compared with standard anti-depressants Hypericum extracts had similar effects'. Based on the clinical trial evidence over-the-counter preparations of $\mathrm{St}$ John's wort are sold for their mood-enhancing properties, although herbal practitioners use the herb for a wider range 
of conditions, including chronic fatigue syndrome and viral infections. Although the antiviral effects are well supported by pharmaceutical studies, the immune-enhancing effects experienced in the clinical setting have yet to be researched.

Saw palmetto is native to the eastern seaboard of North America. The berry is the source of $\beta$-sitosterol, which has, as a single compound, been shown to improve urinary symptoms and flow in benign prostatic hyperplasia according to a systematic review by Wilt et al. (2000). Both nettle (Urtica dioica) root and saw palmetto have been shown to reduce symptoms of benign prostatic hyperplasia in clinical trials and both are rich sources of $\beta$-sitosterol. More than nine double-blind clinical trials have been conducted on saw palmetto, which show a positive effect of a daily dose (9:1 extract (nine parts by weight of the dried herb (or berry) being equivalent to one part by weight of extract); $320 \mathrm{mg} / \mathrm{d}$ ) for 3 months on symptoms of benign prostatic hyperplasia, equivalent to that obtained with finasteride (the generic drug prescribed). In a meta-analysis Boyle et al. (2004) have concluded that men with benign prostatic hyperplasia randomised to take saw palmetto extract '... showed a significant improvement in peak flow rate and reduction in nocturia above placebo ....'

\section{A clinical study on hawthorn}

Studies on single-herb intervention have included the effects of hawthorn (Crataegus laevigata) on hypertension. Traditionally used for the treatment of hypertension, atherosclerosis, poor circulation and heart disease, the actions of hawthorn are focused on the cardiovascular system. The active constituents are mostly flavonoids, on which the extracts are standardised. The physiological actions that have been demonstrated in preclinical studies show antioxidant, smooth muscle relaxant, vasodilatory and hypertensive properties. Although interactions with modern drugs prescribed for cardiac insufficiency have been speculated, none have been reported. Indeed, Tankanow et al. (2003) have shown no interaction between digoxin and hawthorn.

In a pilot study of thirty-six healthy volunteers with mildly-raised blood pressure, who were taking no prescribed medication, a non-significant lowering of resting diastolic blood pressure after administration of a daily dose of $500 \mathrm{mg}$ hawthorn extract (leaves and flowers) for 10 weeks has been reported (Walker et al. 2002). In a followup study seventy-nine subjects with mild hypertension and type 2 diabetes with or without prescribed drug treatment were recruited (Walker et al. 2006). The subjects, $71 \%$ of whom were taking hypotensive drugs, were randomised to take $1200 \mathrm{mg}$ hawthorn extract daily or placebo for 16 weeks. Those subjects on hawthorn ( $n$ 39) were found to have a small but significant reduction $(P=0.035)$ in mean diastolic blood pressure ( $\mathrm{mmHg}$; from 85.6 (95\% CI 83.3, $87.9)$ at baseline to 83.0 (95\% CI $80.5,85.5)$ at outcome) compared with the placebo intervention $(n 40 ; 84.5(95 \%$ CI $82 \cdot 0,87 \cdot 0)$ and $85 \cdot 0$ (CI $82 \cdot 2,87 \cdot 7$ ) respectively; see Fig. 1). No herb-drug interactions were found, there were no effects on liver or kidney function and a similar number

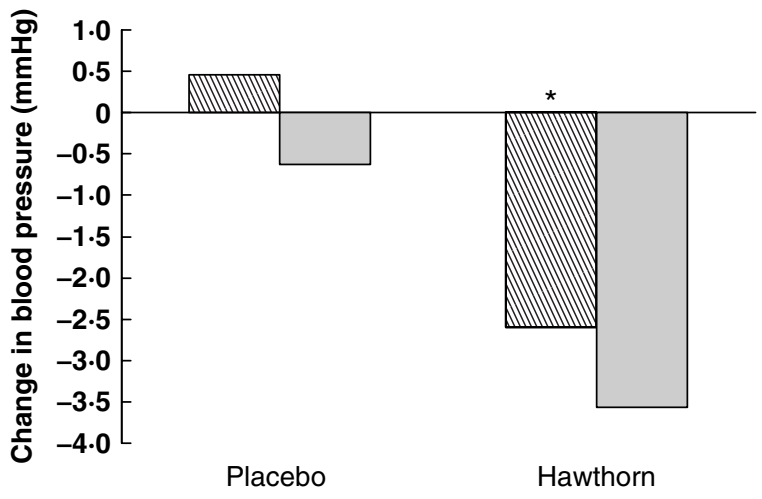

Fig. 1. Change in blood pressure from baseline for seventy-nine subjects with type 2 diabetes after 16 weeks of daily hawthorn (Crataegus laevigata) supplementation compared with placebo. (IIII), Diastolic blood pressure; ( $\square$ ), systolic blood pressure. Mean value for the change in diastolic blood pressure was significantly different from that for the placebo: ${ }^{\star} P=0.035$.

of minor side-effects were experienced in both groups. There were no withdrawals because of adverse reactions in the group receiving hawthorn. These data support the evidence base for the safety of hawthorn.

For a subset of the study group (AF Walker, G Marakis, E Simpson, JL Hope, PA Robinson, R Bundy and HCR Simpson, unpublished results) plasma triacylglycerols were found to have decreased significantly $(P=0 \cdot 015)$ in response to the hawthorn intervention ( $n$ 21; mean (mmol/l) at: baseline, 1.62; outcome, 1.38) compared with the placebo ( $n 19$; mean $(\mathrm{mmol} / \mathrm{l})$ at: baseline, 1.58 ; outcome, 1.88; Fig. 2). A similar response comparison for plasma HDL-cholesterol shows a non-significant increase for the hawthorn subgroup $(P=0.068)$ compared with the placebo. However, for HDL a significant difference $(P=0.015)$ was found at outcome (mean value of $1.29 \mathrm{mmol} / \mathrm{l}$ ) compared with baseline (mean value of

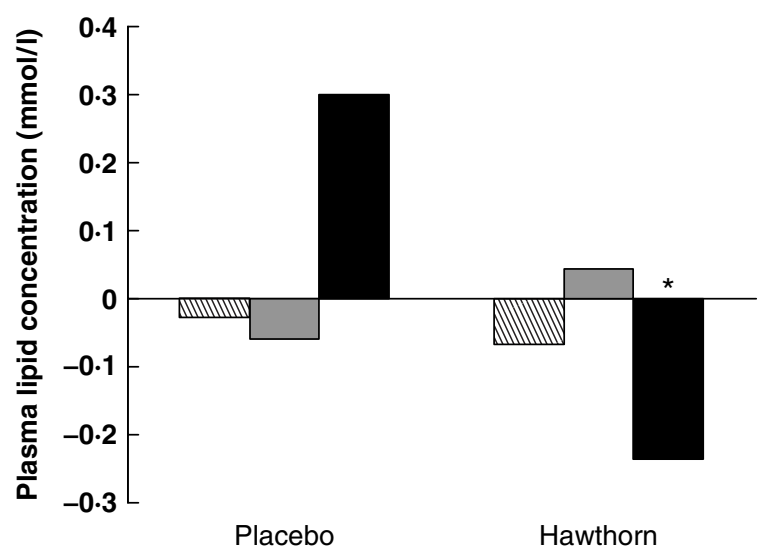

Fig. 2. Changes in plasma lipaemic variables from baseline for a study subset $(n 40)$ of subjects with type 2 diabetes after 16 weeks of daily hawthorn (Crataegus laevigata) supplementation compared with placebo. (IIIII), Total cholesterol; ( $\square$ ), HDL-cholesterol; ( triacylglycerols. Mean value for triacylglycerols was significantly different from that for the placebo: ${ }^{\star} P=0 \cdot 015$. 


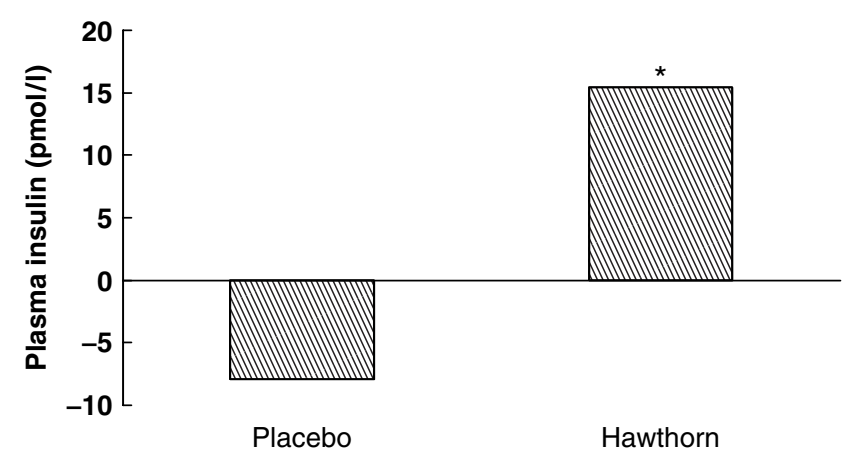

Fig. 3. Changes in plasma insulin concentration from baseline for a study subset $(n 40)$ of subjects with type 2 diabetes after 16 weeks of daily hawthorn (Crataegus laevigata) supplementation compared with placebo. Mean value was significantly different from that for the placebo: ${ }^{\star} P=0.020$.

$1.24 \mathrm{mmol} / \mathrm{l})$, not matched in the placebo group. Favourable lipaemic effects of hawthorn have been suggested previously from a human study (Rigelsky \& Sweet, 2002). As for blood pressure, the lipaemic effects of hawthorn are small, as often found for biomarkers in natural-medicine intervention studies. However, in phytotherapy the mild effects of several herbs are amplified in the clinical situation by the traditional use of herbal combinations.

As far as glycaemic control is concerned fasting blood glucose levels were not found to be affected significantly by intervention. However, the outcome response of mean plasma insulin concentration of the hawthorn subset shows a significant increase $(P=0.020)$ compared with the placebo group (Fig. 3). For the hawthorn subset $(n 21)$ the mean values (pmol/l) were 63.1 at baseline and 73.5 at outcome, while for the placebo subset $(n 20)$ mean values were 72.0 and 66.6 respectively. These findings are surprising and unexpected, although they do concur with results from a study on rats with streptozotocin-induced diabetes, which show potent anti-hyperglycaemic activity of hawthorn (Jouad et al. 2003). This extent of support for pancreatic function in type 2 diabetes is substantial and clearly warrants further study.

\section{Developing an evidence base for phytotherapy}

Studies on single herbal extracts can support the traditional use of herbs, but these studies paint only a partial picture of the traditional use of herbs, administered as mixtures, in phytotherapy. While there is considerable and growing evidence on patient-orientated outcomes of diets such as the Dietary Approaches to Stop Hypertension diet to help inform public health authorities in nutrition, there is no such evidence to support the practice of 'Western' phytotherapy. Although herbal medicine as used in traditional Chinese medicine is better supported by randomised studies, this evidence does not contribute to an evidence base for Western phytotherapy because of the differences in therapeutic approach; Chinese herbal medicine is based on restoration of energy balance (yin-yang) rather than restoration of homeostasis.

\section{Collation of patient case notes}

Collation of patient case notes can be carried out with minimal funding to provide observational evidence to support phytotherapy, as the following example shows. In a retrospective audit of treatment of chronic fatigue syndrome data from on-going clinic case notes of female patients meeting the Centers for Disease Control 1994 classification criteria for chronic fatigue syndrome (Fukuda et al. 1994) at first consultation have been collated (AF Walker, unpublished results). Hence, the main inclusion criterion was persistent or relapsing fatigue for $>6$ months, not alleviated by rest and preventing normal activities. To comply with the Centers for Disease Control classification subjects also had to have experienced at least four of the following: loss of memory or concentration, sore throat, tender lymph nodes, muscle pain, joint pain, headaches, unrefreshing sleep or post-exercise malaise. Eight patients met these criteria and Table 3 shows their details.

Dietary advice was given to increase intake of fruit and vegetables (seven of the eight patients), oily fish (seven of the eight patients) and dairy products (two of the eight patients) and to replace high- $n-6$ PUFA seed oils with olive oil (two of the eight patients). All women were advised to take a multinutrient supplement. Based on the first consultation, in which a non-validated mini-food-frequency questionnaire was completed and health complaints recorded, the following additional supplements were advised: vitamin $\mathrm{C}$ (six of the eight patients), $n-3$ PUFA (six of the eight patients), $\mathrm{Ca}+\mathrm{Mg}$ (six of the eight patients), $\mathrm{Mg}$ (five of the eight patients), vitamin $\mathrm{E}$ (two of the eight patients) and $\mathrm{Cr}$ (one of the eight patients). The most commonlyprescribed herbs used among the eight women in the audit were: St John's wort (all eight patients); echinacea (Echinacea purpurea; five of the eight patients); chaste berry (Vitex agnus-castus; five of the eight patients); astragalus (Astragalus membranaceus; five of the eight patients); ashwanganda (Withania somnifera; four of the eight patients); schizandra (Schisandra chinensis; four of the eight patients); vervain (Verbena officinalis; three of the eight patients). A further twenty-six herbs were prescribed for only one or two women.

The main outcome of the audit was the response to cold viruses. Clinical experience has revealed a distinct change in response to cold viruses by patients suffering chronic fatigue syndrome, whose cycles of remitting and relapsing fatigue can occur as often as every 2 weeks. As relapse often coincides with the occurrence of colds among other family members, it is likely to be related to viral infection. However, patients with chronic fatigue syndrome normally experience few respiratory symptoms, only exacerbation of fatigue. Indeed, it is common to hear patients with chronic fatigue syndrome say 'I have not had a cold for years'. As the patient's health improves, fatigue diminishes and this outcome usually coincides with the appearance of a 'head cold'. Patients may then go through a phase of very frequent head colds, which gradually settle down to one or two per year (as for healthy individuals) as vitality is regained. A search of the literature has revealed no reference to this phenomenon, which is likely to relate to immune competence, although many practitioners are 
Table 3. Progress of eight women with chronic fatigue syndrome treated with phytotherapy and assessed in April 2003

\begin{tabular}{|c|c|c|c|c|c|c|c|c|}
\hline Patient ... & SC & HS & AV & KS & JK & TY & AT & JH \\
\hline Age (years) & 19 & 20 & 27 & 34 & 36 & 48 & 63 & 67 \\
\hline $\begin{array}{l}\text { Date of } 1 \text { st consultation } \\
\text { (month and year) }\end{array}$ & $01 / 2002$ & $09 / 2000$ & $07 / 2000$ & 02/2001 & $02 / 2001$ & $12 / 2000$ & 09/2002 & $11 / 1999$ \\
\hline BMI $\left(\mathrm{kg} / \mathrm{m}^{2}\right)$ & 21 & 18 & 20 & 24 & 24 & 20 & 22 & 20 \\
\hline $\begin{array}{l}\text { Occupation at } 1 \text { st } \\
\text { consultation }\end{array}$ & $U$ & $U$ & $U$ & $A$ & MR & $\mathrm{H}$ & $\mathrm{R}$ & $\mathrm{R}$ \\
\hline $\begin{array}{l}\text { Time from 1st } \\
\text { consultation to 'first' } \\
\text { head cold (months) }\end{array}$ & 5 & 22 & 20 & 20 & 11 & 20 & 4 & 15 \\
\hline $\begin{array}{l}\text { Occupation in April } \\
2003\end{array}$ & US & $U$ & A & A & MR & $\mathrm{H}$ & $\mathrm{R}$ & $\mathrm{R}$ \\
\hline $\begin{array}{l}\text { Practitioner's } \\
\text { assessment of } \\
\text { patient's recovery in } \\
\text { April } 2003(\%)\end{array}$ & 100 & 85 & 90 & 90 & 85 & 100 & 100 & 95 \\
\hline $\begin{array}{l}\text { Comments from } \\
\text { patients on well- } \\
\text { being and/or lifestyle } \\
\text { in April } 2003\end{array}$ & $\begin{array}{l}\text { Enjoying } \\
\text { university } \\
\text { and coping } \\
\text { well }\end{array}$ & $\begin{array}{l}\text { Keen to start } \\
\text { university } \\
\text { course }\end{array}$ & $\begin{array}{l}\text { Coping well } \\
\text { with a new } \\
\text { life }\end{array}$ & $\begin{array}{l}\text { I look happy } \\
\text { and people } \\
\text { notice }\end{array}$ & $\begin{array}{l}\text { Life's a } \\
\text { struggle, } \\
\text { over- } \\
\text { working }\end{array}$ & $\begin{array}{l}\text { Enjoying life } \\
\text { and } \\
\text { playing } \\
\text { tennis } \\
\text { again }\end{array}$ & $\begin{array}{l}\text { Never felt } \\
\text { better }\end{array}$ & $\begin{array}{l}\text { More robust } \\
\text { and } \\
\text { singing in } \\
\text { a choir }\end{array}$ \\
\hline
\end{tabular}

U, unemployed; US, university student; A, administrative post; MR, medical representative; H, Housewife; R, retired.

aware of it. Table 3 shows the time from first consultation to the 'first' head cold among the women in the audit.

Audits of case notes, such as this one, may allow practitioner experience to become available to a wider audience, may inspire further clinical studies and could be carried out prospectively for greater rigour.

\section{Clinical trials of phytotherapy}

Any clinical investigation into the therapeutic potential of the complexity of phytotherapy intervention is fraught with difficulties. Fortunately, Bensoussan et al. (1998) have provided a modus operandi; they have investigated the effects of Chinese herbal medicine in a randomised double-blind trial on 116 patients who fulfilled the Rome criteria of irritable bowel syndrome (Drossman et al. 1994). Patients were randomly allocated to one of three treatment groups: individualised Chinese herbal prescriptions ( $n$ 38); a standard Chinese herbal formulation ( $n 43)$; placebo ( $n$ 35). Patients received treatment as powdered herb capsules (five capsules three times daily) for 16 weeks and were evaluated by both a traditional Chinese herbalist and a gastroenterologist at baseline and outcome. Volunteers were seen on five occasions in consultation with a Chinese herbalist, when progress was assessed and herbal medicine prescribed from a formulary of eighty-one herbs. Practitioners were blinded to the randomisation coding. A dispenser, privy to the coding, fulfilled herbal prescriptions only for those randomised to individualised treatment; other patients received placebo or the standard herbal formula. Compared with patients in the placebo group, those patients in both active treatment groups were found to show improvement in irritable bowel syndrome scores. Although the effects of individualised and standard treatments were found to be equivalent at outcome, at followup 14 weeks after the completion of treatment only the individualised treatment group maintained the improvement.

Using the model of Bensoussan et al. (1998) a randomised pilot study has been undertaken to investigate the effects of practitioner-prescribed phytotherapy in the treatment of osteoarthritis (L Hamblin, A Laird and AF Walker, unpublished results). Twenty adults, previously confirmed by X-ray images as suffering from osteoarthritis of the knee, were recruited from two inner London general practitioner practices, fourteen of whom completed the study per protocol. Subjects continued on any conventional medication, received healthy-eating advice and were given a standard nutrient supplement. In addition, each subject

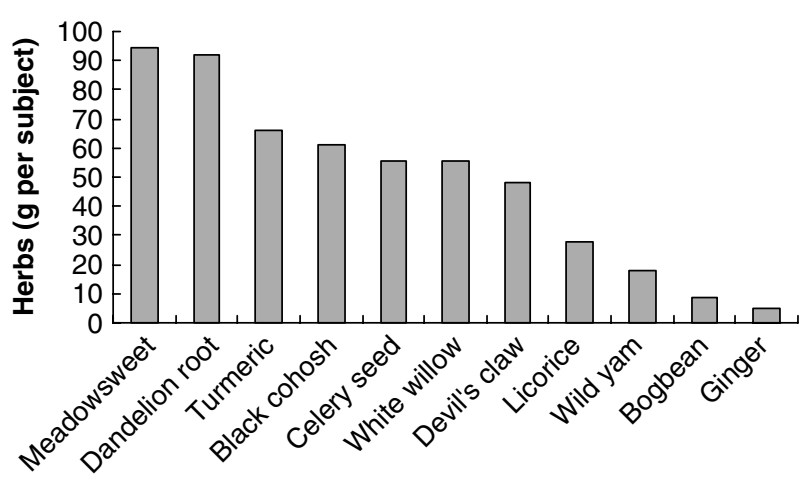

Fig. 4. Average amount of herbs (as dried-herb equivalents) per subject prescribed for the active treatment group ( $n$ 9) during 10 weeks of a pilot study of phytotherapy for osteoarthritis. Meadowsweet, Filipendula ulmaria; dandelion, Taraxacum officinale Weber s.l.; turmeric, Curcuma longa; black cohosh, Cimicifuga racemosa (L.) Nutt.; celery, Apium graveolens; white willow, Salix spp.; devil's claw, Harpagophytum procumbens D.C.; licorice, Glycyrrhiza glabra; wild yam, Dioscorea villosa; bogbean, Menyanthes trifoliata; ginger, Zingiber officinale Roscoe. 


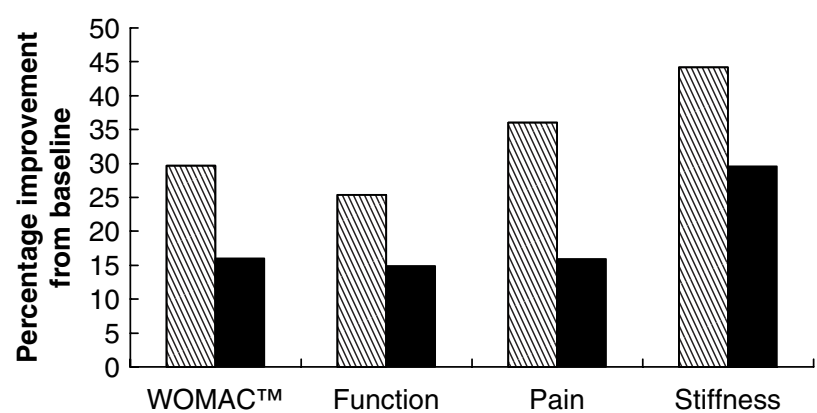

Fig. 5. Improvements from baseline in WOMAC ${ }^{\mathrm{TM}}$ knee health (Bellamy et al. 1988) scores and subscores for patients with osteoarthritis in a pilot study of phytotherapy ( $n$ 9; IIII) compared with placebo treatment $(n 5 ; \boldsymbol{\square})$. The percentage improvement from baseline was significantly different from that for placebo for total WOMAC $^{\mathrm{TM}}$ score $(P=0 \cdot 146)$, function subscore $(P=0 \cdot 188)$, pain subscore $(P=0.143)$ and stiffness subscore $(P=0.060)$. An improvement of $20 \%$ is regarded as clinically-important according to Tubach et al. (2005).

was randomly assigned to receive daily for 10 weeks either individualised herbal medicine, prescribed by a herbal practitioner from a limited formulary of eleven herbs, or placebo in the manner of Bensoussan et al. (1998). At baseline and outcome subjects completed the WOMAC ${ }^{\mathrm{TM}}$ knee health (Bellamy et al. 1988) and the 'measure your medical outcome profile' (Paterson, 1996) questionnaires; for the latter, patients defined two symptoms of main concern to them.

Fig. 4 shows the average weight of herbs (g dried herb) prescribed per subject in the herbal treatment group during the study. While no response difference was observed between the two groups compared with baseline, mean knee health ( $n$ 9) was found to indicate a promising $(P=0.060)$ improvement in the WOMAC ${ }^{\mathrm{TM}}$ stiffness subscore at outcome (Fig. 5). Clinically-important improvements (>20\%; Tubach et al. 2005) in the mean WOMAC $^{\mathrm{TM}}$ total score and all subscores were observed

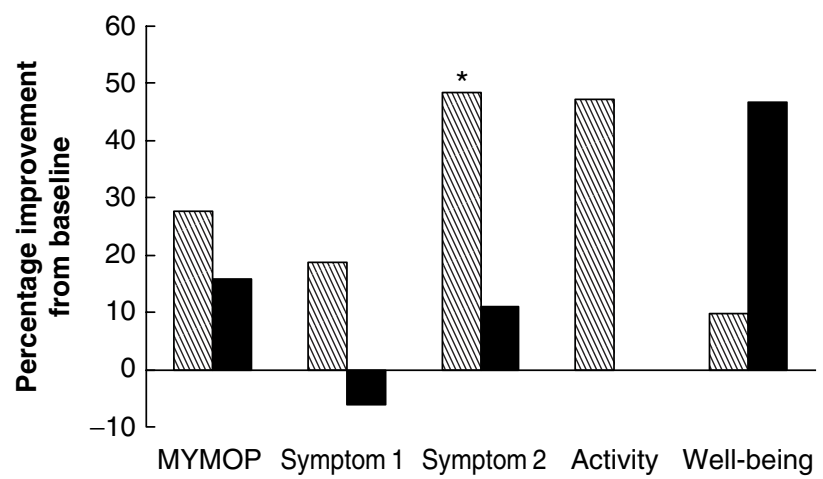

Fig. 6. Improvements in 'measure your medical outcome profile' (MYMOP; Paterson, 1996) total and subscores for patients with osteoarthritis in a pilot study of phytotherapy ( $n$ 9; IIIII) and placebo $(n 5 ; \boldsymbol{\square})$ treatment. The percentage improvement from baseline for symptom 2 was significantly different from that for placebo: ${ }^{\star} P=0.008$. The percentage improvement from baseline for activity was significantly different from that for placebo $(P=0.064)$. for the active treatment group at outcome compared with baseline, while comparable values for the placebo group (n 5) suggest a clinically-important improvement only in the stiffness subscore. The mean 'measure your medical outcome profile' symptom 2 subscore (Fig. 6), mostly related to osteoarthritis, indicates significant improvement at outcome ( $P=0.008$, respectively) compared with baseline for those taking herbal medicine but not for those taking placebo. Larger adequately-powered studies based on this model could provide a way forward for investigating patient-orientated outcome of complex holistic therapeutics.

\section{Conclusions}

The art of herbal medicine (phytotherapy) involves a complex therapeutic intervention in which the mild effects of single natural interventions are built into an effective individualised therapeutic regimen. Clinical experience shows that this approach is applicable for a wide range of disease conditions, but it remains to be proven through scientific enquiry. Although an increasing science base supports the efficacy of individual herbs and defined herbal combinations as treatment for various conditions, evidence for the efficacy of individually-prescribed herbal combinations, as used in Western phytotherapy is scarce. The present paper describes several lines of enquiry through which the evidence base for the efficacy of phytotherapy could be strengthened.

\section{Acknowledgements}

My grateful thanks to co-researchers: Rafe Bundy, Hugh Simpson, Eleanor Simpson, George Marakis, Louise Hamblin and Alex Laird.

\section{References}

Bellamy N, Buchanan WW, Goldsmith CH, Campbell J \& Stitt LW (1988) Validation study of WOMAC: a health status instrument for measuring clinically important patient relevant outcomes to antirheumatic drug therapy in patients with osteoarthritis of the hip or knee. Journal of Rheumatology 15, $1833-1840$

Bensoussan A, Talley NJ, Hing M, Menzies R, Guo A \& Ngu M (1998) Treatment of irritable bowel syndrome with Chinese herbal medicine: a randomized controlled trial. Journal of the American Medical Association 280, 1585-1589.

Birks J, Grimley EV \& Van Dongen M (2002) Ginkgo Biloba for Cognitive Impairment and Dementia. The Cochrane Database of Systematic Reviews 2002, issue 4, art. no. CD003120. Chichester, West Sussex: John Wiley \& Sons Ltd.

Bone K (2003) A Clinical Guide to Blending Liquid Herbs: Herbal Formulations for the Individual Patient. Edinburgh: Churchill Livingstone.

Boyle P, Robertson C, Lowe F \& Roehrborn C (2004) Updated meta-analysis of clinical trials of Serenoa repens extract in the treatment of symptomatic benign prostatic hyperplasia. British Journal of Urology International 93, 751-756.

Drossman DA, Richter JE, Talley NJ, Thompson WG, Corazziari E \& Whitehead WE (editors) (1994) The Functional 
Gastrointestinal Disorders: Diagnosis, Pathophysiology, and Treatment - A Multinational Consensus. Boston, MA: Little, Brown \& Co.

European Commission (2004) Directive 2004/24/EC of the European Parliament and of the Council of 31 March 2004, amending, as regards traditional herbal medicinal products, Directive 2001/83/EC on the Community code relating to medicinal products for human use. Official Journal of the European Union L136, 85-90.

European Scientific Cooperative on Phytotherapy (2003) Monographs: The Scientific Foundation for Herbal Medicinal Products, 2nd ed. New York: Thieme.

Fukuda K, Straus SE, Hickie I, Sharpe MC, Dobbins JG \& Komaroff A (1994) The chronic fatigue syndrome: a comprehensive approach to its definition and study. Annals of Internal Medicine 121, 953-959.

Griggs B (1997) New Green Pharmacy: Story of Western Herbal Medicine. London: Vermilion.

Jouad H, Lemhadri A, Maghrani M, Burcelin R \& Eddouks M (2003) Hawthorn evokes a potent anti-hyperglycemic capacity in streptozotocin-induced diabetic rats. Journal of Herbal Pharmacotherapy 3, 19-29.

Kasper S \& Dienel A (2002) Cluster analysis of symptoms during antidepressant treatment with Hypericum extract in mildly to moderately depressed out-patients. A meta-analysis of data from three randomized, placebo-controlled trials. Psychopharmacology 164, 301-308.

Linde K, Berner M, Egger M \& Mulrow C (2005) St John's wort for depression: meta-analysis of randomised controlled trials. British Journal of Psychiatry 186, 99-107.

Mills S \& Bone K (2000) Principles and Practice of Phytotherapy. Edinburgh: Churchill Livingstone.

Nicolaou N \& Johnston GA (2004) The use of complementary medicine by patients referred to a contact dermatitis clinic. Contact Dermatitis 51, 30-33.

Paterson C (1996) Measuring outcomes in primary care: a patient generated measure, MYMOP, compared with the SF-36 health survey. British Medical Journal 312, 1016-1020.
Rigelsky JM \& Sweet BV (2002) Hawthorn: pharmacology and therapeutic uses. American Journal of Health-System Pharmacy 59, 417-422.

Sacks FM, Appel LJ, Moore TJ, Obarzanek E, Vollmer WM, Svetkey LP et al. (1999) A dietary approach to prevent hypertension: a review of the Dietary Approaches to Stop Hypertension (DASH) Study. Clinical Cardiology 22, Suppl., 1116-1110.

Tankanow R, Tamer HR, Streetman DS, Smith SG, Welton JL, Annesley T, Aaronson KD \& Bleske BE (2003) Interaction study between digoxin and a preparation of hawthorn ( $\mathrm{Cra}$ taegus oxyacantha). Journal of Clinical Pharmacology 43, 637-642.

Tubach F, Ravaud P, Baron G, Falissard B, Logeart I, Bellamy N, Bombardier C, Felson D, Hochberg M, van der Heijde D \& Dougados M (2005) Evaluation of clinically relevant changes in patient reported outcomes in knee and hip osteoarthritis: the minimal clinically important improvement. Annals of Rheumatic Diseases 64, 29-33.

UK Parliament (1977) The Medicines Act 1968. Order 1977. Statutory Instrument 1977 No. 2128 (C. 71). London: H. M. Stationery Office.

Walker AF, Marakis G, Morris AP \& Robinson PA (2002) Promising hypotensive effect of hawthorn extract: a randomized double-blind pilot study of mild, essential hypertension. Phytotherapy Research 16, 48-54.

Walker AF, Marakis G, Simpson E, Hope JL, Robinson PA, Hassanein M \& Simpson HCR (2006) Hypotensive effects of hawthorn for diabetic subjects taking prescription drugs: a RCT. British Journal of General Practice (In the Press).

Williamson EM (2001) Synergy and other interactions in phytomedicines. Phytomedicine 8, 401-409.

Williamson EM (2003) Potter's Herbal Cyclopaedia. Saffron Walden, Essex: C W Daniel Co Ltd.

Wilt T, Ishani A, MacDonald R, Stark G, Mulrow C \& Lau J (2000) Beta-Sitosterols for Benign Prostatic Hyperplasia. Cochrane Database of Systematic Reviews 1999, issue 3, art. no. CD001043. Chichester, West Sussex: John Wiley \& Sons Ltd. 